\title{
Columbus de Werner Egk: una ópera sobre Cristóbal Colón en la Alemania nazi
}

\author{
José Elías GuTIÉRREZ MEZA \\ Romanisches Seminar \\ Ruprecht-Karls-Universität Heidelberg \\ elias.gutierrez@uni-heidelberg.de
}

\begin{abstract}
RESUMEN
Columbus, primera ópera del músico alemán Werner Egk (1901-1983), fue compuesta como ópera radiofónica. Su primera transmisión se realizó en 1933, poco tiempo después del nombramiento de Adolf Hitler como canciller de Alemania, y fue duramente criticada. Sin embargo, un año después se presentó como concierto en Múnich y en 1941 se estrenó una versión para escenario en la Ópera de Fráncfort. Incluso se representó tras la caída del régimen nazi y el compositor preparó una tercera versión en 1951. En este trabajo se estudia cómo esta ópera, ajena e inclusive contraria a los principios ideológicos del nazismo, consiguió insertarse dentro de su cultura oficial.
\end{abstract}

Palabras clave: Cristóbal Colón, ópera alemana, música del Tercer Reich, el descubrimiento de América en las artes.

\section{Werner Egk's Columbus: an opera about Christopher Columbus in Nazi Germany}

\begin{abstract}
Columbus, German musician Werner Egk's (1901-1983) first opera, was composed as a radio opera. Its first transmission was in 1933, shortly after the appointment of Adolf Hitler as Chancellor of Germany, and was harshly criticized. However, a year later the opera was performed as concert in Munich and in 1941 a version for the stage was premiered at the Frankfurt Opera. Columbus was represented even after the fall of the Nazi regime and the composer prepared a third version in 1951. In this paper we study how this opera, outside and even contrary to the ideological principles of Nazism, got inserted into its official culture.
\end{abstract}

Keywords: Christopher Columbus, German opera, music of the Third Reich, the discovery of America in the Arts. 


\section{Egk y su Columbus}

Werner Joseph Mayer nació en Auchsesheim (Baviera) en 1901. Su apellido Egk fue originalmente un pseudónimo creado a partir de las iniciales de los nombres de su esposa, la violinista (Geigerin) Elisabeth Karl, que él empleó desde su matrimonio en 1923. Estudió música en Fráncfort y Múnich, donde fue discípulo de Carl Orff. En 1932 compuso su primera ópera, Columbus, la que, como se trató de un encargo de la Radio de Baviera, surgió como ópera radiofónica (Funkoper ${ }^{1}$ ). Fue transmitida por primera vez el 13 de julio de 1933, dentro del ambiente todavía trastocado por el ascenso al poder de Hitler ocurrido el 30 de enero del mismo año. Meses después, el 6 de abril de 1634, se realizó su primera representación como concierto en Múnich, bajo la batuta del propio Egk. Contratado por la Ópera de Fráncfort, el 13 de enero de 1942 se estrenó una nueva versión (la primera destinada a un escenario: Bühnenfassung I) con el título Columbus. Bericht und Bildnis. Con esta segunda versión, sin embargo, no concluyen las transformaciones de la ópera. En 1951 se estrenó en Berlín una tercera versión (y segunda versión para escenario: Bühnenfassung II), donde el ballet toma un rol importante, al punto que la ópera aparece clasificada como Ballett-Oratorium. Como se ve, Columbus fue un trabajo sobre el que Egk volvió en diferentes momentos de su carrera, la cual (como se nota también por las fechas) empezó a desarrollarse a la par del ascenso de los nazis al poder, pero que no se detuvo con el final de la guerra en 1945. Otra característica que distingue a Columbus dentro de las óperas de Egk es su libreto, escrito por el propio compositor «usando documentos auténticos y literatura en castellano antiguo» ${ }^{2}$. Para el resto de sus óperas Egk tomaría como base obras literarias.

Los documentos auténticos y en castellano antiguo a los que Egk habría recurrido serían los Diarios de Colón y los escritos de Bartolomé de las Casas. De acuerdo con Jouve-Martín, el compositor habría también empleado las biografías sobre el almirante que circulaban en dichos años en Alemania, especialmente Christoph Columbus. Der Don Quichote des Ozeans (1929) del novelista alemán Jakob Wassermann (2009: 776), pues existen coincidencias entre esta biografía y la ópera. Sin embargo, dichas coincidencias se pueden explicar por el hecho de que el novelista siguió y citó frecuentemente los textos de Colón y Las Casas. Por ejemplo, al inicio de la segunda parte de la ópera, el canto de Colón: «Also werde ich bald das Paradies auffinden an einem Ort, wohin niemand gelangen kann, als durch den göttlichen Willen» (Egk 1942: 12); coincide con una cita de los diarios en la biografía de Wassermann (1992: 143), que corresponde al tercer viaje: «creo que allí es el Paraíso Terrenal, a donde no puede llegar nadie salvo por voluntad divina» (Colón 2000: 238). Del mismo modo, la representación de la colonización como la conversión del paraíso en un infierno está presente en Egk y Wasserman, pero tiene su origen en Las Casas. Por ello, creo que una mejor evidencia de la huella de Wassermann en la

${ }^{1}$ Sobre el rol social de la radio en la cultura alemana de dicha época, remito al trabajo de JouveMartín 2009: 772-774.

2 Así se declara en el libreto, al final de la página donde aparece la lista de personajes. 
ópera se encuentra en la inclusión del texto del requerimiento. En el capítulo «Los indios y el oro», cuando se refiere al momento del primer encuentro de Colón con la población autóctona de la isla Guanahaní, la voz del biógrafo deja lugar a la del propio Wassermann:

Yo era un niño de diez años cuando leí por primera vez cómo Colón tomó posesión «legalmente» de Guanahaní. Recuerdo que la expresión «legalmente» me asombraba tanto que varios días di vueltas sobre esto. En mi ingenuidad me preguntaba cómo esto sería posible, pues ya en la isla vivía gente y posiblemente desde hace muchos años. Me asombraba sobre todo la obviedad del suceso y que los españoles no hubiesen al menos preguntado si el territorio ya pertenecía a alguien. En este caso me parecía sumamente raro hablar de legalidad y los conceptos se me confundían. Fue evidentemente una impresión infantil. Lo comprendí más tarde, especialmente porque este acontecimiento en todos los libros era descrito con la misma naturalidad y porque no encontré a ninguna persona que compartiese mi asombro. (Wassermann 1992: 75) ${ }^{3}$

Después, en el capítulo «La terrible realidad», al comentar los inicios de la colonización, Wassermann salta al año 1509 (más allá de los límites cronológicos de su biografía), en el cual aparece el requerimiento: «documento de carácter jurídico que debía leerse en voz alta a los indios con el fin de que se rindieran antes de entrar en batalla. Su objetivo [era] la justificación de la guerra, en el caso de que los indios se opusieran a la Iglesia y a la entrada de sus misioneros» (Serna 2012: 290).

Este documento, según Wassermann, «demasiado significativo y revelador como para ser ignorado», que no tiene equivalente en los anales de la historia y que empaña el pasado de la humanidad (1992: 114), es colocado por Egk precisamente en el momento que en la ópera corresponde a la mencionada interrupción en la biografía; es decir, en el segundo acto, cuando un heraldo lee la declaración de posesión (reemplazada por el requerimiento) a los primeros nativos que se encuentran con la expedición de Colón.

El hecho de que Egk al referirse a las fuentes de su ópera omitiese la biografía de Wassermann y enfatizase que había recurrido a textos auténticos y en español antiguo tiene una explicación. Por una parte, esta omisión no solo subrayaba la base histórica de su ópera, sino también, como Ernst Krause apunta, quería enfatizar que dicha materia histórica había sido tratada de la forma más objetiva posible al evitar seguir el punto de vista de una sola persona (1971: 106), lo que está en sintonía con la impronta del teatro épico de Bertolt Brecht sobre Columbus. La otra razón obedece al complicado contexto histórico que rodeó el estreno de la ópera. Con el ascenso de los nazis al poder, se inicia en marzo de 1933 la campaña contra el espíritu antialemán, que lleva a las quemas de libros de autores judíos, marxistas, pacifistas y opositores al régimen, que se produjeron el 10 de mayo de 1933 en toda Alemania. Al ser Wassermann de ascendencia judía, su obra fue también blanco de estos atentados, por lo que hubiese sido peligroso para Egk declararlo como fuente de su ópera.

3 Aquí y en los otros textos en alemán copio mis traducciones al español. 
Como mencioné, Columbus sufrió dos transformaciones: de ópera radiofónica a ópera-oratorio y después a oratorio-ballet. Los cambios realizados entre la segunda versión y la tercera fueron exclusivamente musicales y escénicos, de modo que el libreto de ambas se mantuvo sin variación alguna, como he podido verificar ${ }^{4}$. Columbus está compuesto de tres partes. La primera está formada a su vez por cinco escenas que dramatizan los primeros encuentros de Colón con los Reyes Católicos, la presentación de Colón ante el consejo que desestima su empresa, el fallido enrolamiento de marineros (finalmente reemplazados por prisioneros) y la despedida y partida de Colón y su expedición. En medio de estas escenas se insertan conversaciones (Gespräche), que son escenas dialogadas, en las que dos locutores (Sprecher) se refieren a la acción. Dichos diálogos están ausentes en la segunda parte de la ópera, compuesta por una única escena, en la que se representa el arribo y desembarco de Colón en tierras americanas, así como su primer encuentro con los naturales, donde se inserta el texto del requerimiento. En el tercer acto, formado por tres escenas, se representa el jubiloso recibimiento de Colón en España tras su primer viaje, la preparación de la traición contra él por los españoles establecidos en las primeras colonias y su encuentro en el momento de su muerte con el fantasma de la reina Isabel. Entre estas escenas se intercalan tres conversaciones ${ }^{5}$.

La inclusión de estas partes dialogadas recuerda el neoclasicismo del Oedipus Rex de Igor Stravinski. En esta ópera-oratorio en latín, un narrador relata, en la misma lengua del público, la historia. Sin embargo, mientras en Oedipus la narración permite que el público se concentre en la música; en Columbus la función de los locutores va más allá y, en este sentido, apela al efecto de extrañamiento (Verfremdungseffekt) del teatro épico de Brecht, pues establece una distancia entre el público y la representación (Brecht 2004: 83-85). Estas conversaciones, que interrumpen el fluir de la música, recuerdan al oyente/espectador el carácter artificial de la ópera. Asimismo, los locutores no solo resumen lo ocurrido o anuncian lo que está por ocurrir, sino también lo comentan desde puntos de vista diferentes. Así, para el segundo locutor, Colón «está lleno de la sabiduría de los profetas», mientras que para el primero: «Su sabiduría es palabrería de marinero que ha aprendido en los bares de los puertos». Mediante esta suerte de polifonía de pareceres contrarios, se evita inclinar al público hacia una determinada posición, de modo que el oyente/espectador pueda formarse su propio juicio. En Columbus, mientras las escenas cumplen con la parte del Bildnis (retrato), anunciada en el subtítulo de la ópera, al imitar mediante el canto, la actuación y (en el caso de la tercera versión) el baile determinados momentos de la historia de Colón; las conversaciones corresponden al Bericht (informe), pues siguiendo su sentido de «relato objetivo de un suceso o hecho» ${ }^{6}$ buscan referir imparcialmente dicha historia al comentarla desde perspectivas divergentes.

${ }^{4}$ He comparado el libreto publicado en 1942 con la grabación de Múnich de 1963, publicada por el sello Orfeo (que corresponde a la versión de 1951) y no he hallado diferencias.

${ }_{5}^{5}$ El quinto diálogo aparece al inicio del tercer acto y antes de la primera escena.

${ }^{6}$ Aquí y en el caso de Gestalt utilizo las definiciones del diccionario Duden. 
Aunque Columbus nació fuera de la cultura y, sobre todo, la ideología nazi, podía ser leído desde dicha perspectiva racista. La colonización española en la ópera no se presenta como el nacimiento de una nueva civilización aria, lo cual está en sintonía con las ideas de Adolf Hitler en Mein Kampf sobre la colonización de América. Hitler explicaba racialmente la diferencia en el desarrollo de los Estados Unidos con respecto al resto de naciones americanas. Mientras que los colonizadores de los primeros contaban con la importante presencia de elementos germanos (y, por ende, arios) que se mezclaron mínimamente con las poblaciones autóctonas, los colonizadores de los segundos fueron de origen latino y se unieron a gran escala con las poblaciones aborígenes. Por ello, la lujuria que caracteriza a los emigrantes encaja dentro de esta imagen negativa de los colonizadores españoles, pues Hitler veía en la mezcla de razas (y como ejemplo proponía precisamente el caso de Latinoamérica) la causa de la ruina de una raza superior, de la cual ni siquiera la raza aria estaba libre: «El germano del continente americano, que permaneció racialmente puro y sin mezcla, se elevó a ser amo del mismo; como tal se mantendrá mientras tampoco caiga en la deshonra de la sangre» (Hitler 1943: 313-314).

De este modo, el paraíso descubierto por Colón deviene pronto en un infierno. Con todo, ninguna de las escenas de la ópera representa la directa participación del descubridor en tal proceso, la cual solo conocemos de forma indirecta por los emigrantes (completamente contrarios a él y que, por ello, no representan un testimonio neutral) y los locutores. Ante la falta de un retrato, el informe polifónico de los locutores se convierte en el testimonio más fiable para juzgar el papel de Colón en la destructiva colonización. En el sexto y penúltimo diálogo, las acusaciones contra el almirante son para el segundo locutor (el más favorable a él): «Oscuros rumores, funestas profecías». En cambio, el primero (el más contrario y reacio a admitir sus logros) reconoce su grandeza: «fue grande en descubrimientos» para inmediatamente sentenciar: «pero lamentablemente incompetente en la administración» (Egk 1942: 17).

Asimismo, desde la perspectiva racial de la ideología nazi, el fracaso de Colón se explicaba evidentemente por su raza. La realización de su sueño superaba sus capacidades, pues, al no ser ario, no era apto para fundar una gran cultura en América. Por ello, su empresa estaba inevitablemente condenada al fracaso. Pero, más allá de ese enfoque racial, ciertamente en la misma naturaleza de Colón reside parte del origen de su caída. Como se señala en la última conversación, tras ser depuesto del gobierno, los portugueses descubrieron la verdadera ruta occidental a las Indias, mientras que otros (en una clara referencia a Américo Vespucci) se encargaron de reestructurar los conocimientos sobre la verdadera naturaleza del mundo. Colón, sin embargo, se niega a reconocer estos hechos y se mantiene empecinadamente en la creencia de que los territorios a los que él había llegado eran las Indias. Tal es su terquedad que el segundo locutor (hasta ese momento siempre favorable a él) lo critica duramente: «Testarudo como un niño insiste en su ridícula creencia en el cuento de hadas del descubrimiento de la ruta occidental» (1942: 21). Así, la que fue su principal virtud (su voluntad indomable de realizar su proyecto) al final de la ópera se convierte en su principal defecto, ya que le impide ver las verdaderas repercusiones de su logro: el descubrimiento de un nuevo continente. En la escena final de la 
ópera, Colón muere pobre y abandonado, presa de los remordimientos del infierno en que se han convertido sus Indias.

\section{La recepción de Columbus}

Si bien, en lo que se refiere al libreto, la representación de la historia en Columbus encaja dentro de la ideología del Tercer Reich, la parte musical de la ópera no se adecuaba de igual manera al ideal de música propugnado por los nazis. Como recoge Krause, dentro de la complicada atmósfera política en que se estrenó la ópera, la prensa del partido se refirió en duros términos a ella (1971: 111-112). También negativa fue la crítica de Otto Oster en Zeitschrift für Musik, para quien Columbus apuntaba a la forma más que al contenido, lo que convertía a los personajes en tipos exangües. Asimismo, si bien Oster reconocía que el recurso del informe era parte esencial de la radio, este limitaba las posibilidades expresivas de la ópera (1933: 1234).

Estos supuestos defectos de Columbus, junto con la mencionada influencia de Stravinski y la de Aufstieg und Fall der Stadt Mahagonny de Kurt Weill y Bertolt Brecht, que Oster percibía en las escenas de los soldados y de los emigrantes (1933: 1234), habrían provocado la cancelación de la presentación de la ópera como concierto en Múnich, programada para el 30 de noviembre de 1933. Sin embargo, Egk persistió, de modo que finalmente consiguió que la ópera se presentase en $1934 \mathrm{y}$, asimismo, que el Völkischer Beobachter (el periódico oficial del partido nazi, editado por el propio Alfred Rosenberg) le dedicase una reseña positiva. Si bien esto representaba la inclusión de su Columbus dentro de la cultura oficial del Tercer Reich (Jouvé Martín 2009: 783), las críticas hacia su obra por su impronta modernista se mantuvieron (Kater 2000: 6).

La posición de Egk dentro de la cultura musical oficial mejoraría con su siguiente ópera. Si Columbus sintonizaba con la primera parte del leitmotiv nazi Blut und Boden (sangre y tierra), Die Zaubergeige (El violín encantado), estrenada el 22 de mayo de $1935^{7}$, lo hacía con la segunda parte: la tierra. El campesino Kaspar, en busca de una vida mejor, abandona el campo y emprende un viaje, en el que encuentra al Erdgeist (espíritu de la tierra) Cuperos que le obsequia con un violín con poderes mágicos que se mantendrían siempre que renuncie al amor. Con tal instrumento, Kaspar consigue fama y también gana el amor de la aristócrata Ninabelle, lo que provoca la pérdida de sus poderes, precisamente cuando es capturado por la policía por haber supuestamente robado al prestamista Guldensack («bolsa de monedas»). El malentendido se aclara con la intervención de Cuperos, que le ofrece a Kaspar el violín con sus poderes restaurados. Pero el campesino decide no tomarlo y vuelve a su tierra para vivir una modesta pero feliz vida junto con Gretl, otra campesina como él. Si, por una parte, la renuncia al amor recordaba el gran tema de Der Ring des

\footnotetext{
7 Jouvé Martín adelanta erróneamente la fecha del estreno al 20 de mayo (Ludewig 1966: 13; Krause 1971: 190).
} 
Nibelungen de Richard Wagner, compositor venerado por Hitler (Hitler 1943: 232; Splitt 2006: 27-30); por otra parte, el regreso final del protagonista a la vida en el campo encajaba con la revalorización oficial del campesinado y la agricultura por parte de los nazis, pues el mundo rural era visto como la auténtica representación de la esencia del pueblo alemán (Sala Rose 2003: 340$)^{8}$. Die Zaubergeige fue un éxito y Egk fue incluido entre los compositores a los que se encargó la música para los Juegos Olímpicos de Berlín de 1936.

\section{Conclusiones}

Columbus de Egk es un buen ejemplo de los contradictorios entretelones detrás de las obras de los artistas que, sin un compromiso inicial y claro con el nazismo, consiguieron establecerse en el centro de la vida cultural fijada de acuerdo con dichas directrices ideológicas. A primera vista, parecería inaudito que una ópera con un libreto que presenta llamativas coincidencias con la obra de un autor prohibido (Wassermann) y con una musicalización en la que se percibía la influencia de compositores también censurados por el régimen (Stravinski, Weill) se insertase dentro de la cultura oficial de la Alemania nazi. Para entender este caso es necesario recordar que la ópera se estrenó en los inicios del Tercer Reich, es decir, en el tiempo en el que se empezaron a sentar las bases del aparato estatal nazi y, a la vez, de su política cultural, los que, no obstante, en los siguientes años no dejaron de causar más de una confusión. No solo era complicado distinguir musicalmente entre la innovación saludable y la experimentación degenerada, sino que tanto los dirigentes como los expertos tenían opiniones diferentes sobre tales conceptos (Griffin 2010: 412). A esto se añade que la actividad musical en Alemania era tan activa y descentralizada que era imposible mantener un completo control sobre ella (Kater 1997: 189). El caso de Stravinski es un buen ejemplo de las contradicciones en las que el sistema podía incurrir. Aunque el compositor ruso, por sus simpatías fascistas, se puso pronto a disposición del régimen, para lo cual acreditó sus orígenes arios y aristocráticos, fue incluido en la exposición Entartete Musik (Música degenerada) de Düsseldorf en 1938. Sin embargo, ese mismo año dirigió y grabó su ballet Jeu de Cartes con la Filarmónica de Berlín (Fernández de Larrinoa 2010: 103).

El empleo como fuente de la obra de Wassermann prueba que Columbus no nació como una obra alineada con la ideología nazi. Es posible leerla desde tales coordenadas, pero el texto del libreto sustenta también una lectura desde una posición contraria a dicha ideología. En efecto, la inclusión del texto del requerimiento y la representación del infierno indiano suponen un cuestionamiento tanto a la legalidad de la conquista como a la subsecuente colonización que, al abstraerse de las

\footnotetext{
${ }^{8}$ Richard Walter Darré, ingeniero agrónomo, había asociado a los pueblos germanos con el sedentarismo, en oposición al nomadismo de los judíos. Con la fundación del Rasseamt (Instituto Racial) de las SS, buscó crear un campesinado de raza pura, que constituyese una nueva aristocracia (Sala Rose 2003: 335-344, 431).
} 
coordenadas históricas del argumento, se convierte en una crítica contra el imperialismo y, en el contexto de aquellos años, contra el proyecto expansionista nazi. Sin embargo, Egk decidió desarrollar su carrera dentro de la cultura oficial del régimen, por lo que sus siguientes óperas se alinearon conscientemente con dicha ideología, desde luego, sin rebajar su calidad artística al punto de convertir su arte en mera propaganda.

A manera de epílogo: Peer Gynt, su tercera ópera (1939), incluía una alegoría burlesca de los elementos degenerados de la República de Weimar (Levi 2000: 154). A pesar de la controversia que suscitó, fue bien recibida por Hitler y Joseph Goebbels (Krause 1971: 101). En 1941 Egk reemplazaría a Paul Graener en la dirección de la sección de compositores de la Reichsmusikkammer, la institución nazi creada para promover la música alemana. Un año después se reestrena Columbus en Fráncfort y recibe entusiastas elogios de los mismos medios que criticaron negativamente su estreno radial. Tras la caída del régimen, Egk fue exonerado en los tribunales de desnazificación ${ }^{9}$. Continuó su vida artística hasta su muerte en 1983, tiempo en el que, además de ocupar importantes puestos, recibió distintos honores y reconocimientos.

\section{Referencias bibliográficas}

BRECHT, Bertolt (2004): Escritos sobre teatro. Genoveva Dieterich (trad.). Barcelona: Alba. Colón, Cristóbal (2000): Los cuatro viajes. Testamento. Consuelo Varela (ed.). Madrid: Alianza.

Custodis, Michael y Friedrich GeIGER (2013): Netzwerke der Entnazifisierung. Münster: Waxmann.

Duden. Deutsches Universalwörterbuch (2015). Mannheim: Bibliographisches Institut.

EGK, Werner (1942): Columbus. Bericht und Bildnis. Mainz: B. Schotts's Söhne.

- (2001): Columbus. Orfeo. CD.

FERNÁNDEZ DE LARRINOA, Rafael (2010): «Los cantos de sirena del fascismo». Audio Clásica 159: 98-103.

GRIFFIN, Roger (2010): Modernismo y fascismo. Jaime Blasco Castiñeyra (trad.). Madrid: Akal.

HitLER, Adolf (1943): Mein Kampf. Leipzig: Franz Eher Nachf.

Jouve-MARTín, José (2009): «Werner Egk’s opera Columbus (1933/1942) and the Recreation of the Discovery of America in Nazi Germany». Bulletin of Spanish Studies 86, 6: 769-792.

KATER, Michael H. (2000): Composers of the Era Nazi. New York: Oxford University Press.

- (1997): The Twisted Muse: Musicians and their Music in the Third Reich. New York: Oxford: Oxford University Press.

Krause, Ernst (1971): Werner Egk. Oper und Ballett. Berlin: Henschelverlag.

LEVI, Erik (2000): «Opera in the Nazi Period», en John London (ed.): Theatre under the Nazis, pp. 136-186. Manchester: Manchester University Press.

LuDEWIG, Wolfgang (1966): Werner Egk. Opern, Ballette, Konzertwerke. Mainz: B. Schotts's Söhne.

Oster, Otto (1933): «Werner Egks Columbus. Zum Problem der Funkoper». Zeitschrift für Musik 100, 12: 1233-1235. 
Salas Rose, Rosa (2003): Diccionario crítico de mitos y símbolos del nazismo. Barcelona: Acantilado.

SÁNCHEZ LANSCH, Enrique (2012): Das Reichsorchester. Arthaus. Blu-ray.

SERNA, Mercedes (ed.) (2012): La conquista del Nuevo Mundo. Textos y documentos de la aventura americana. Barcelona: Castalia.

SPLITT, Gehrard (2006): «Hitler und die Musik», en Das Dritte Reich und die Musik. pp. $27-$ 38. Berlin: Nicolai.

WASSERmAnN, Jakob (1992): Christoph Columbus. Eine Biographie. München: DTV. 